\title{
Always there
}

\author{
Ravi Shankar $\mathbf{P}^{* 1}$, Arya $S^{2}$
}

Xavier University School of Medicine, Oranjestad, Aruba

1Professor, Department of Medical Education, Xavier University School of Medicine, Oranjestad, Aruba ${ }^{2}$ Fifth semester medical student, Xavier University School of Medicine, Oranjestad, Aruba

The role of women in healthcare and medicine has become a widely debated topic recently. We live in an age where women are assuming increasingly important positions in healthcare. The National Institutes of Health (NIH) - a world leader in medical research makes a vital contribution toward improving the healthcare of Americans and individuals around the world. Dr. Ruth Kirchstein provided direction and leadership to $\mathrm{NIH}$ through most of the second half of the twentieth century. The book 'Always There' by Alison Davis PhD, tells the story of the truly remarkable Dr. Kirchstein.

Dr. Kirchstein was of Jewish heritage, and the child of immigrant parents. She had to overcome a number of prejudices and obstacles to succeed, and build her legacy. During her tenure at NIH, Dr. Kirchstein was involved in the development of an effective polio vaccine; was the first woman director of a major institute at $\mathrm{NIH}$; and initiated training programs which provided opportunities to disadvantaged students. She was involved with the Women's Health Initiative, and with recombinant DNA research.

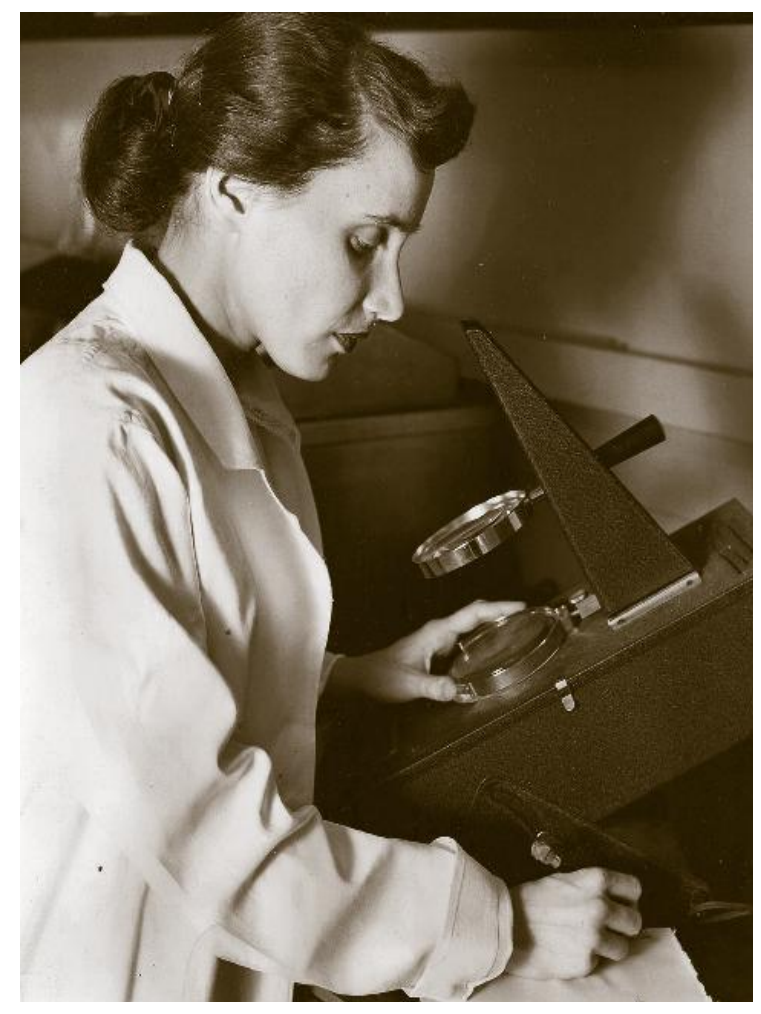

Ruth loved the challenge and mystery of medical research (Credit: NIH History Office)

The book is divided into seventeen chapters which follows the life of Dr. Kirchstein, chronologically from her childhood. The foreword mentions how Ruth was 'always there,' and how her overflowing enthusiasm enriched the lives of everyone around her. 
In the 1950s, polio was still a major public health problem in the United States (US), especially affecting children. The images of children crippled by the disease and requiring an iron lung to breathe due to paralysis of their respiratory muscles, inspired fear. During the 1950s, women were principally confined to their homes, and uncommon in professional fields; and minority groups were under-represented in most endeavors. People of African-American heritage were widely discriminated against. The case of two separate water fountains, as described in the book, one for the whites and the other for coloreds, may shock many readers.

Chapter 1 titled, 'Coming of Age,' describes the childhood of this remarkable woman. The story of how Ruth's father immigrated to the United States, and how, because he was not sure of his family name, mumbled a name beginning with ' $\mathrm{K}$ ' and the name of 'Kirchstein' (which means cherry stone in German), was provided by the immigration attendant, makes for an interesting reading.

Ruth spend her childhood in Brooklyn, New York, and her childhood was affected by the great depression and discrimination, because of her Jewish heritage. Getting admitted to medical school was a challenge for Ruth. Both because of the existing quota system for Jewish students, and because of her female gender. Finally, Tulane University School of Medicine invited her to an interview. Ruth was accepted and did her best to adapt to the demands of the medical curriculum.

The second chapter deals with Ruth's marriage to Al Robson. The author describes how like the few female doctors of the time, Ruth was pressured to pursue a career in specialties regarded as more suitable to women - like Pediatrics or Obstetrics and Gynecology. Chapter three describes the couples' move to NIH, and how as they stood on the steps of a building in the sprawling campus, instantly knew they had made the right decision. Science, music, and family were among the three main commitments of the couple, and they shared a variety of interests. Chapter 4 focuses on the 'Seeds of Social Justice'. Ruth and her husband recognized poverty and inequality as the root cause for many diseases, and were involved in making things better for the disadvantaged.

Even within the NIH, it was difficult for women to gain prominence and recognition for their work. Chapter 5 describes Ruth's work at NIH and how she spend her life chasing down disease. Microbial diseases were very frequent, and the chapter also briefly describes the discovery of antibiotics. Her main work with polio, in those days a 'crippling disease,' is described in the next chapter. The US President, Franklin D Roosevelt, suffered from polio and used a wheelchair. He was especially interested in finding a cure for and reducing the impact of this dreaded disease.

Old photographs are an integral part of the book, and the one showing a hospital ward populated entirely by patients in iron lungs because of respiratory paralysis due to polio, was so powerful, that it was disturbing to see. Various polio vaccines were developed in the 1950 s and the cases of paralysis which developed following administration of the Salk vaccine to children, created a public health nightmare. Adverse reactions to vaccines are not uncommon, even today, and still attract media attention. Poliovirus strains have mutated and changed over the ensuing 
years, and recently a new strain of the polio vaccine has been widely introduced.

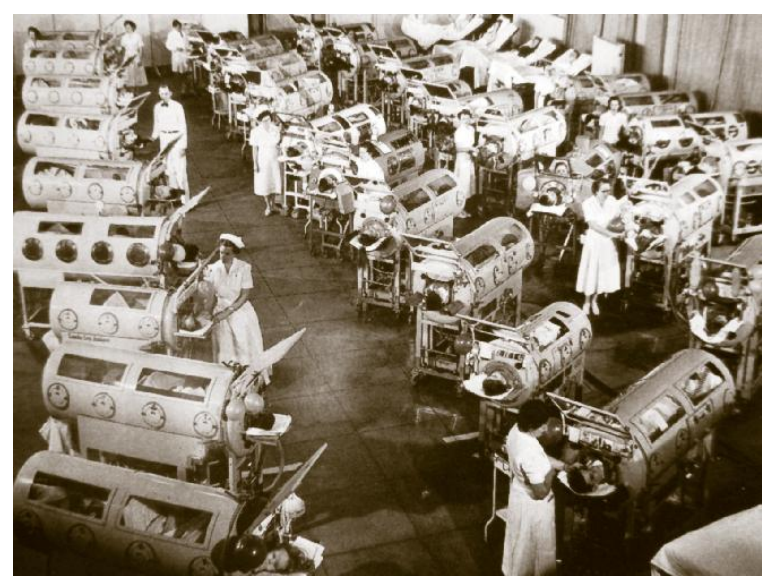

This 1953 hospital ward housed dozens of people with polio who required iron lung machines to breathe. (Credit: FDA)

Ruth lived for 83 years - and those years brought forth tremendous changes in science, politics, and society. In 1926, the year of her birth, the majority of scientists were male, and Caucasians. NIH started its existence as the laboratory of hygiene, with a handful of male scientists. In the 1940s, DNA had been isolated, though little was known about its structure and function.

In the 1950s, when she started working at $\mathrm{NIH}$, the double helical structure of DNA was published, and a polio vaccine had been developed. Ruth's leadership role at $\mathrm{NIH}$, and her nurturing style of leadership has been well described throughout the book. The later chapters of the book describe her fight with cancer, and her time as the director of NIH. NIH provides research grants to universities, to provide support to set up high quality training programs - and the majority of these are proudly designated as Ruth L Kirchstein national research service awardees.

The story of Dr. Ruth Kirschstein - an iconic leader at NIH - a minority who broke thru many barriers, is a real inspiration. It has been tastefully designed, and the many black and white, and sepia toned photographs, all add to the beauty of the book. All those interested in science will enjoy reading this well-written literature.

\section{AUTHOR'S CONTRIBUTION}

PRS and SA- were involved in reading the book, writing the review and revising it for critical intellectual content. Both the authors have read and approved the final submitted version.

\section{SOURCE OF SUPPORT: None}

CONFLICT OF INTEREST: None declared

About the book : Davis AF. Always there the remarkable life of Ruth Lillian Kirchstein, M.D. 2011: National Institutes of Health. ISBN 978-0-9797540-4-3. The book is freely available from https://www.nih.gov/aboutnih/who-we-are/always-there-remarkablelife-ruth-lillian-kirschstein-md and can be downloaded for free from https://www.nih.gov/sites/default/files/abo ut-nih/Always There 0.pdf

\section{Correspondence to:}

Prof. P Ravi Shankar

Xavier University School of Medicine \#23, Santa Helenastraat, Oranjestad Aruba, Kingdom of the Netherlands. E-mail: ravi.dr.shankar@gmail.com 